\title{
Acúmulos e vazios da pesquisa sobre o rock argentino
}

\author{
Adrian Pablo FanJuL
}




\section{Resumo}

Com base em um amplo levantamento em centros de pesquisa e bibliotecas universitárias argentinas, apresenta-se um panorama da recepção crítica do rock argentino no meio acadêmico, em diversas áreas de conhecimento. Os resultados mostram que a crítica gera em torno do movimento uma "tradição em formação", com eixo nas ciências sociais e da comunicação e com os seguintes traços predominantes: abordagem do rock fundamentalmente como delimitador de "identidades sociais" de diverso tipo, periodizações do gênero em paralelo com as mudanças nos regimes políticos, consideração exclusivamente temática e conteudística de suas letras. Tentamos demonstrar que esses traços concorrem para uma delimitação do rock como fenômeno exclusivamente da mídia de massa, que coloca em segundo plano sua função estética e sua vinculação com outras séries artísticas.

\section{Palavras chave}

rock argentino, crítica cultural, crítica de arte, discurso

\section{Abstract}

Based on a comprehensive study developed in research centers and Argentine libraries, a panorama about the critical response regarding the Argentine rock in the academic circles has been traced in several different fields of knowledge. The results show that the criticism has generated a "developing tradition" about the movement mainly in the Social and Communication Sciences and it has presented the following predominant traits: approaching rock essentially as a determinant of several kinds of "social identities", periodization in the genre following the political regimes and sole consideration of the theme and content of the lyrics. We have tried to demonstrate that these traits contribute to a delimitation of rock as an exclusive phenomenon of the mass media, which relegates its aesthetic function and its relationship with other artistic series to secondary importance.

\section{Keywords}

argentine rock; cultural criticism; art criticism; discourse 


\section{Introdução}

$\mathrm{E}$

ste trabalho tenta mostrar um "estado da arte" da pesquisa acadêmica e crítica sobre o rock da Argentina no seu próprio

país. Está baseado em uma ampla pesquisa bibliográfica realizada em bibliotecas, acervos e centros de pesquisa em diversas áreas de conhecimento, nas principais cidades da Argentina, para a qual contamos com financiamento da Fundação de Amparo à Pesquisa do Estado de São Paulo (FAPESP). No levantamento foram revisados mais de 60 trabalhos, incluindo dissertações de mestrado, trabalhos de conclusão de graduação, teses de doutorado, livros, capítulos e artigos em revistas científicas, muitas delas de circulação limitada a uma região específica desse país.

Trata-se de uma leitura crítica e orientada por uma pergunta central de pesquisa: qual tem sido a reflexão sobre a dimensão verbal no rock, especificamente sobre as discursividades que produzem sentido na sua materialidade lingüística? Cremos que esse fio condutor, conseqüência do interesse especifico com que, como estudiosos das discursividades urbanas da Argentina, aproximamo-nos do rock desse país, dá pertinência a este trabalho, no sentido de ele não ser uma soma de resenhas.

Quanto ao objeto "rock argentino", seria contraditório começar definindo-o, logo em um artigo que se propõe a descrever como ele é recortado pelas ciências humanas e pela crítica. Com efeito, o mais substancial das possíveis definições será mostrado ao longo do texto. Porém, prevendo um leitor não imerso na cultura argentina contemporânea, começaremos esclarecendo sucintamente que, enxergado quer como gênero da música popular urbana, quer 
como o movimento sociocultural constituído pelo seu público e seu espaço de circulação, trata-se de um dos fenômenos culturais de maior abrangência e permanência desse país nos últimos quarenta anos. Cremos que sobre isso não haveria divergência entre os múltiplos pontos de vista aos quais faremos referência aqui.

Tentaremos demonstrar que, na recepção critico-investigativa desse fenômeno, apesar de não haver uma tradição que intervenha como modelo forte de referência, pode perceber-se o predomínio de uma abordagem fincada em categorias da Sociologia e dos estudos sobre meios de comunicação, acompanhada de algumas constantes, como a periodização em relação aos regimes políticos e a leitura conteudística, que deixaram a dimensão discursiva como um campo pouco explorado.

\section{Uma leitura motivada}

É importante levar em conta que, ao fazer a proposta de observar como o discurso acadêmico argentino recorta o objeto "rock nacional", é nosso olhar de observador que instaura esse lugar de encontro. Não há um trabalho preexistente ao nosso que tenha assumido essa tarefa, e também não houve até agora grandes espaços de encontro multidisciplinar sobre o tema do rock argentino que debatessem $o$ assunto ou ao menos oferecessem um panorama menos motivado pelo olhar de um determinado pesquisador. É importante levar em conta, precisamente, que atua no nosso trabalho a perspectiva de alguém que pesquisa a partir de um campo determinado das ciências humanas, a Lingüística, e mais especificamente os estudos discursivos. Não duvidamos de que essa procedência é eficaz sobre o modo em que classificaremos o material levantado.

Interessa-nos também esclarecer o alcance que daremos ao termo "crítica" nesta descrição. Entenderemos por tal o trabalho de um pesquisador sobre objetos da cultura com o objetivo de produzir um ensaio como tipologia textual. Diferenciamos esse formato de outros que também fazem parte de nosso levantamento, como o texto científico em forma de dissertação, tese ou artigo; mas essa diferença

Significação $27 \cdot 128$ 
diz respeito apenas ao tipo textual e não implica, de maneira nenhuma, ver o crítico como "não pesquisador", ou a crítica (assim entendida) como "não pesquisa". Parece-nos pertinente esse esclarecimento porque não foi de nosso interesse um outro tipo textual, amplamente circulante em torno dos produtos da cultura de massa, que na mídia também é chamado de "crítica": o comentário do jornalismo especializado na mídia de ampla difusão ${ }^{1}$. Em síntese, nosso levantamento foi sobre a pesquisa argentina, em forma de texto científico e/ou de ensaio crítico, sobre o rock nacional. Quase toda ela é produzida no âmbito acadêmico em sentido amplo, ou em meios relacionados a ele, ou em diálogo com ele.

Nosso levantamento mostrou o claro predomínio, no universo pesquisado, de um campo de saber ligado às ciências sociais, com a Sociologia como centro e alcançando as denominadas "ciências da comunicação". O ponto 2 , a seguir, com seus itens internos, está dedicado a descrever esse enfoque, que vemos já com traços de tradição em formação. Como descrevemos no subtítulo, parecenos um continuum em que essas disciplinas se vinculam para tratar de um objeto. Apesar da heterogeneidade desse leque de perspectivas metodológicas, vemo-lo como um campo em formação no que tange à apreensão e delimitação desse objeto pontual, o rock argentino, porque, como descreveremos, há constantes solidárias na criação de uma racionalidade resultante. Uma delas, que nos leva ao que trataremos no ponto 3 , é a elipse da materialidade verbal, da letrística, como ordem de considerações. Assim, o ponto 3 trata sobre os estudos que tentam abordar de diferentes maneiras essa materialidade verbal, e que se colocam (poucas vezes explicitamente), em um espaço diferente do outro campo.

1. Também não fez parte de nosso levantamento o que Dlaz (2005, p. 50-61) denomina acertadamente como "crítica de rock": os textos com forma de comentário que, nas revistas produzidas no interior do próprio movimento vão criando um cânon. Não desconhecemos que, em periodos de maturidade do movimento, essa "crítica de rock" tem muitos canais comunicantes com a produção ensalstica de pesquisadores que aqui sim consideramos. 


\section{Os traços de um continuum}

\subsection{Pioneiros}

Em 1985 aparece o primeiro texto de caráter científico sobre o rock argentino. Pablo Vila, no contexto de uma série de livros sobre movimentos sociais, publica "Rock nacional. Crónicas de la resistencia juvenil" (Vila, 1985). O extenso ensaio é o terceiro dentro de um livro do Centro Editor da América Latina, em sua coleção "Biblioteca Política Argentina", e que contém outros dois ensaios, um que introduz a problemática dos movimentos sociais na Argentina, e outro sobre as mulheres na transição à democracia.

Damos esses detalhes sobre o suporte porque ele parece emblemático como ponto de partida: é desse lugar de explicação que o rock nacional é percebido pela primeira vez como objeto de estudo. E trata-se de uma proposta com nítidas marcas enunciativas da Argentina da imediata pós-ditadura: o movimento, a resistência, a transição, propostos como campo de pesquisa. Vale salientar, também, que é um texto que se propõe como análise do movimento rock, que inclui não apenas nem principalmente os compositores $e$ as bandas, mas o público que se agrupa em torno delas.

O texto de Vila, nas suas 60 páginas, introduz alguns dos tópicos que reaparecem até hoje nas produções que analisamos. Praticamente do começo instala a problemática da criação de um "nós" contra um "eles"; oposição que retoma ao longo do texto todo, reformulando os atributos de cada um dos seus pólos. No entanto, não se trata de uma reflexão articulada em torno da categoria de "identidade", termo poucas vezes mencionado no texto, e sobre o qual não há fragmentos de discussão teórica. Em compensação, muitas vezes se propõe a categoria de "ator coletivo". Outro traço que será retomado pelos trabalhos posteriores é um modo de periodização do rock nacional realizada completamente em paralelo com os momentos de um regime político: a ditadura militar de 19761983. Vejam-se alguns dos subtítulos da obra: "El terror y la construcción del 'nosotros' (1976-1977)"; “Afianzamiento del régimen 
y crisis del rock (1978-1979)"; "Crisis del Proceso y resurgimiento del rock. (1980-1981)". "Guerra de Malvinas y difusión masiva del rock (1982-1983); "El rock en democracia (1984)".

Dois anos depois, em outro meio de difusão, Vila (1987) publica outro trabalho pioneiro, "El rock, música argentina contemporánea", que, a diferença do anterior, não aborda o movimento em geral senão o gênero musical mesmo. Nesse texto é dito pela primeira vez em termos de uma taxonomia genérica algo que já fazia parte (e faz parte ainda) do que a comunidade interpretativa entendia por delimitação do que é ou não é rock nacional. Com efeito, não se compreende, na Argentina, por "rock nacional" um determinado ritmo ou modo de composição, senão uma identificação com modos de produção e circulação, com âmbitos de execução da música, com posturas ideológicas de outras expressões "rock" no mundo, com a estética dessas expressões, com linhagens em relação a antecessores. Do ponto de vista da materialidade sonora, o que cai sob a denominação "rock nacional" é extremamente heterogêneo, incluindo rock, balada, folk de cunho estadunidense, blues, fusões com folclore argentino, com jazz, com tango, com diversas formas de canção popular anterior (rancheira, valsinha), com ritmos caribenhos, uruguaios, brasileiros, com aproximações da música erudita via a influência do rock sinfônico inglês dos 70 , e outras expressões. Afirma Vila nesse texto:

A lo largo de las páginas que siguen, se intentará demostrar cómo la particular estética del género intimamente ligada a un determinado tipo de relación social-determina que el movimiento de rock nacional, sin ser estrictamente rock en lo musical, aunque si lo es en lo ideológico, no puede adscribir a otra cosa que a la música argentina contemporánea. (1987, p. 24)

O terceiro trabalho pioneiro foi o de Alabarces (1993), até hoje o texto acadêmico mais difundido na produção sobre o gênero. Cremos, também, que é o que inicia essa "tradição em formação" que antecipamos no ponto anterior, sem que isso signifique, de maneira 
nenhuma, responsabilizá-lo pela repetição abusiva ou vulgarizada que, como veremos no ponto seguinte, caracteriza uma parte dessa tradição. Veja-se como ele delimitava, em 1993 (p. 12-14), o programa de sua tentativa:

La bibliografia sobre el rock nacional, no por abundante dejó de ser precaria. Generalmente producida desde adentro (músicos, periodistas especializados, testigos amigos) esa serie de textos mantuvo su oscilación entre la reivindicación acritica y el anecdotario. [...] $\mathrm{Me}$ preocupan otras zonas, aquellas que las lecturas han dejado más abiertas. Especialmente cómo juega el rock, cómo juegan todos los fenómenos que el nombre rock nacional reúne, en una dimensión cultural, en la construcción de identidades e imaginarios de las culturas juveniles en Argentina.

Alabarces demarca uma linha divisória que tenta instaurar e fundar a cientificidade na bibliografia sobre rock nacional. $E$ faz isso a partir de um referencial da pesquisa cultural de cunho sociológico, delimitando lócus identitários, tanto do movimento quanto de suas "divisões", mediante oposições semânticas deduzidas de seus discursos. Também trata da relação entre rock e contexto político a partir da análise de contradições, virtude dialética que reaparece em poucos dos trabalhos posteriores que analisam essa relação.

Em vários momentos realiza um trabalho específico sobre a letrística, e nesse sentido é o seu o primeiro texto em que a dimensão lingüístico-discursiva é trazida à tona. Sua explicação das ressemantizações da "cidade", por exemplo, esboça uma procura de regularidades transversal a cada letra e à temática de cada uma. Mas o próprio objetivo geral visado faz com que a categoria privilegiada quanto ao discursivo seja a de "tópico" (locus amoenus, por exemplo), distanciando-se da consideração da forma poética. 
2.2 Manifestação de ideologias, espaço de identificações

A questão da identidade social, como existente estável ou nos conceitos mais dialéticos de "processo de identificação" ou de "construção de identidades", está no centro de grande número dos trabalhos que se propõem a abordar o rock nacional. É na década de 1990 que começa uma produção relativamente constante desses trabalhos. A dimensão ideológica é, neles, a que gera os maiores interrogantes. A dimensão discursiva, quando considerada, é vista como expressão transparente da ideologia descrita. Praticamente os únicos elementos da materialidade discursiva das letras que esses trabalhos consideram são os segmentos em que as "identidades" construídas se denominam ou metaforizam.

Nesse modelo, e sem que nosso comentário signifique desmerecer virtudes que sem dúvida esses trabalhos mostram para aquilo que pontualmente se propuseram, encontramos os textos de Cicalese e Nogueira (1998), Di Marco (1994), Bustos Castro (1994), Molinari (2000), Sosa (1997), Neila (2002), e Follari (1998). Vale a pena, sobre alguns deles, realizar comentários adicionais.

En Cicalese e Nogueira (1998, p.133), o rock nacional aparece como portador e voz de uma identidade estável e dada a priori: "Existe una identidad nacional que se enfrenta paulatinamente con las tendencias internacionales." (p. 140, grifo nosso).

Bustos Castro aborda, em uma seção de seu trabalho, o que chama de "lenguaje rocanrol". Ele se mostra restringido a unidades lexicais, muitas delas "gírias" de uso mais ou menos generalizado, e sem que no texto haja referência pontual a nenhuma letra. A autora faz, a respeito, um paralelo com "a linguagem do tango". Vale a pena mencionarmos que também em estudos sobre o tango é comum a redução da "linguagem" do gênero ao lexical, por meio das gírias. $\mathrm{O}$ procedimento parece repetir-se no tratamento do rock nacional em vários trabalhos, e existe até um "glossário" para o vínculo de ambos os gêneros (Gobello e Oliveri, 2001). Parece-nos que no que tange ao rock nacional, a redução se justifica menos ainda do que no tango, já que mesmo o conhecimento empírico do gênero mostra que as 
gírias caracterizadas como "roqueiras" são ocasionais na textura das letras, encontrando-se muito mais na linguagem do público ou dos compositores quando falam para a mídia, fora de sua composição musical ${ }^{2}$.

Um caso particular, dentro da tendência que descrevemos neste ponto, é o de Beltrán Fuentes (1989), em que o ideológico se apresenta não mediado pela categoria de "identidade", provavelmente pelo fato de o livro ser anterior ao auge dessa categoria nos estudos sociais e políticos. O lugar privilegiado para o acompanhamento da evolução ideológica do movimento é, como aponta o autor, "a temática das canções". O modo em que ele conclui a introdução é, do nosso ponto de vista, fundador para uma articulação de objetos (temasperíodos-ideologia) que, com formas diferentes, se manifesta em boa parte do material que estamos analisando.

La periodización que hemos elaborado para el rock se ha hecho siguiendo dos pautas: la masividad que éste va alcanzando $y$, sobre todo, el contenido temático de las letras de las canciones. Veremos que ambos elementos están relacionados con el proceso histórico del pais (op. cit., p. 8).

Com efeito, essa articulação é para nós a que orienta o continuum entre as conceitualizações sobre construção de identidades e os estudos aplicados sobre meios de comunicação em que circula, com notável recursividade, a pesquisa sobre o rock nacional. Nos próximos dois apartados trataremos dos outros dois lugares do continuum: as periodizações e a centralidade do "temático".

2. Para pensar uma relação entre essas gírias e o que na produção letrística efetivamente aparece, encontramos produtiva uma observação em Kozack (200, p.180) sobre uma rejeição ao sentido instalado na "razão", que nas letras toma formas múltiplas de "sinonímia" com as gírias, em outros termos, que funciona parafrásticamente em relação a elas. 


\subsection{Periodizações: regime político e mercado}

Como explicamos, as delimitações de períodos para a longa história do rock argentino são traçadas guardando correspondência com a mudança de regime político. $\mathrm{O}$ "rock sob a ditadura" vai de 1976 a 1983, quando começa o "rock sob a democracia". Nesse último ponto de divisão é levado em conta, também; o mercado. No ano de 1982, prólogo da queda da ditadura e verdadeiro final da censura e da repressão, a não emissão de música em inglês durante a Guerra das Malvinas favorece imensamente a difusão do rock nacional na rádio, difusão até então limitada a algumas emissoras. O rock nacional consolida seu perfil de massa, instalando-se com mais força no mercado. Não negamos a relevância desse momento, mas é a partir dessa confluência entre fatos políticos e fatos do mercado como critério de periodização que, do nosso ponto de vista, cria-se um terreno fértil para que o rock nacional seja pensado quase exclusivamente como fazendo parte da série histórica da mídia de massa, definindo-se por estar mais ou menos inserido nessa mídia, $\mathrm{e}$ apagando-se sua relação com séries artísticas (musical, literária). Veremos a seguir alguns exemplos, e no ponto seguinte, tentaremos demonstrar como essas periodizações são solidárias com abordagens exclusivamente temáticas da letrística do rock.

Já mencionamos esse tipo de periodização em Vila e Beltrán Fuentes. Ela é reproduzida em Páramos (1998), e em geral, nos outros ensaios incluídos em De Nápoli (1998). Em particular, vemos um extremo dessa lógica em Ogando (1998, p. 199), que chega a formular com ela uma denominação: "Las letras de la decadente dictadura militar también hacian un llamado a la concientización" (grifo nosso).

A periodização segundo o acontecer no regime político continua para as posteriores "etapas" dentro do regime constitucional iniciado em 1983. Em Sosa (1997), por exemplo, vemos que "la desconfianza en la clase política" (p. 22) delimitaria um período do rock, o que vai de 1986 a 1989.

A classificação em função de períodos políticos e da relação com o mercado traz, para alguns trabalhos da década de 1990, um 
novo lugar identitário: o "alternativo" e sua negação, o "adaptado". É interessante observar como essa classificação, em si mesma mercadológica porque só é formulável na relação com o mercado, conduz o pesquisador que a assume como critério na direção da perspectiva do próprio movimento, da reprodução de seus lugares comuns, da atitude laudatória em relação com o "alternativo", ou da tentativa de reconhecimento de "autenticidade" ou "falsidade" entre aqueles que assim se proclamam. Desse modo, a atitude crítica a respeito das composições fica seriamente comprometida, e não casualmente é esse um dos lugares onde o discurso dos jornalistas e biógrafos permeia o trabalho de pesquisadores (pelo geral, iniciais) sobre o rock.

Queremos esclarecer que não negamos que o movimento rock e ainda as composições de rock possam ser um espaço de reflexão sobre os processos de identificação no espaço social da Argentina ou de qualquer outro país; cremos apenas que essa relação não é mecânica nem direta, senão mediada pela ordem do discurso. Também não duvidamos de que experiências como a do terrorismo de estado instaurado pela ditadura militar de 1976-1983 produzem efeitos sobre a arte que é pertinente e possível indagar. Mas pensamos que essa herança não seguirá nem respeitará a cronologia dos regimes, e que ao instalar-se nas composições, por adquirir uma natureza discursiva, articular-se-á conflitivamente com o que já está na série, e sobretudo, não se oferecerá à evidência da "declaração".

A única maneira de sustentar a idéia de um rock que evidenciaria identificações sociais em consonância com o momento político é fazendo omissão de sua materialidade. Cremos que é nessa materialidade, tanto no não verbal do gênero (o musical, o corporal) quanto no verbal que aqui nos convoca, que aparecerão transversalidades, repetições que remetem a uma memória sóciohistórica (Pêcheux, 1990; Guimarães, 2002) não cronológica nem regida pelos "conteúdos", relações parafrásticas não previsíveis a partir da inscrição política ou mercadológica. Enfim, uma discursividade não "independente" da dimensão ideológica, mas sim com relações contraditórias com ela. 


\subsection{A centralidade do "temático"}

Como já afirmamos, nos enfoques predominantes que estamos analisando, a referência à letrística do rock é feita quase exclusivamente sobre seus "temas", ao ponto de que mesmo em trabalhos que declaram ter as letras como um de seus objetos, poucos fragmentos são efetivamente postos sob análise.

O temático chega a aparecer como a explicação geral da linguagem no rock. Em Martinez Mendoza (1994, p. 97-104) a proposta de uma "semiose" do rock começa estabelecendo a necessidade de referir-se a "características enunciativas, retóricas y temáticas" (98), mas de fato é o temático o que domina a descrição, vinculado, diga-se de passagem, aos momentos dos regimes políticos. Na hora de referir-se à "enunciação", trabalha-se apenas com a relação músico-público, deslocando-se ao contexto do recital. Quanto à dimensão retórica, descrevem-se, com importante generalização, estratégias narrativas das quais não se oferecem exemplos concretos (102), e afirma-se que o rock tem "un lenguaje propio" com criação de palavras novas, também não exemplificadas. Encerra o subitem sobre "semiose" propondo que no rock "El uso frecuente de metáforas sirve para expresar cosas que no se pueden decir directamente." (102). A seleção operada na redução das potencialidades da metáfora, sua utilidade para o que não poderia ser dito, parece-nos harmônica com o modo de recortar o rock que estamos descrevendo: objeto de circulação mediática, espaço de expressão política transparente.

Em Cicalese e Nogueira (1998), o próprio gênero é definido e diferenciado de outros pelos temas de que trataria. Depois de um subtítulo denominado "Nuestra clasificación de la música joven" (p. 132), afirmam:

Hemos partido de una primera gran división que trasciende los géneros. Se trata, por un lado, del rock, el blues y el pop, generalmente producidos por jóvenes y con temáticas variadas (temas sociales, cuestionamiento al sistema y a la autoridad, religión, droga, etc.). Luego, 
englobamos a los cantantes netamente comerciales, generalmente melódicos y sustentados en una imagen sensual, circunscripta a temáticas amorosas.

A definição, extremo da tendência que estamos analisando, deixaria fora do rock nacional uma imensa parte de sua produção de todas suas épocas, dedicada a "temas amorosos". Pensamos que essa formulação é o ponto ao que conduz uma dinâmica instalada na "tradição em formação" que propomos em 1, porque encontramos, sim, em outros trabalhos, um certo negligenciamento ou um "fora de foco" para as produções em que a delimitação de identidades ou a vinculação com o momento político não se oferece à evidência do "temático". No texto já referido de Martinez Mendoza (1994), elas são apontadas como "pasatistas" (99). E em geral nos trabalhos que, como detalhamos no ponto anterior, estabelecem para o rock uma periodização por regime político e tema, o efeito é que uma parte da produção é desconsiderada ou cai sob denominações como "intimista", "abstrata" ou "filosófica".

É que a própria periodização em função dos regimes políticos ou mesmo das conjunturas dentro dos regimes, leva a uma leitura quase exclusivamente temática. $O$ rock é abordado apenas como produto da mídia que seleciona seus temas e seu dizer no dia-a-dia institucional. Apaga-se, assim, seu estatuto artístico ou, quanto menos, sua "função estética" (Mukarowsky, 1977).

\subsection{As "identificações" e a crescente desigualdade argentina}

Em meados da década de 1990 aparece uma nova delimitação nos discursos do rock nacional. No próprio campo discursivo do movimento, observável na mídia e na fala do público roqueiro, começa a enunciar-se um rock outro, que receberá principalmente a denominação de "rock chabón"

3. Esclarecemos que a palavra "chabón" circula na Argentina pelo menos desde começos do século XX, em princípio para referir-se a um individuo, Como outras 
como veremos, outras como "barrial" ou "cervecero". Alguns comentaristas tentam localizar sob essa denominação bandas e autores específicos.

Em geral, todos os pesquisadores que lemos, incluindo os que localizamos na "tradição em formação" que estamos analisando, quando abordam o tema rejeitam, cremos que acertadamente, que essa classificação possa caracterizar com regularidade a produção de um setor delimitado de bandas ou de compositores. Novamente é Vila, no caso juntamente com Pablo Semán (2001), quem encara com abrangência este fenômeno. Assim caracterizam o rock chabón (p. 225-226):

Desde un punto de vista sociológico es un fenómeno crucial dentro del actual contexto en el que se forman las vertientes culturales de los sectores populares. Por un lado, es el rock de los que han visto heridas gravemente sus perspectivas de integración social en virtud de un proceso socioeconómico que, al mismo tiempo que liquida el empleo, rebaja la figura culturalmente consagrada del trabajador, santifica exigencias de consumo que frustran más que satisfacen. Por otro lado, es el rock de los que al mismo tiempo responden $y$ en esa respuesta afirman y transforman núcleos positivos de la cultura popular. [...] [El rock chabón] da luz al tono ambiguo, más bien polivalente, con que los jóvenes de sectores populares se relacionan con la democracia, con el desmantelamiento de los últimos pero importantes vestigios del Estado integrador, y con los imaginarios históricos (expresados en interpelaciones

gínas de valor similar no espanhol coloquial de diversas regiões (quía, tio, pana, etc.), "chabón" pode ser também um vocativo. Por associar-se com uma discursividade de bairro, de classes médias-baixas e classes baixas, e dentro delas com um ethos juvenil (apesar de que a geração que pôs a circular o termo no campo do rock já beira os 40-50 anos), seu uso adjetival na expressão "rock chabón" estabelece uma identificação com a representação desses setores. 
y narrativas que le son caracteristicas) generados por la experiencia peronista y que alimentaban los sueños de integración, más o menos igualitaria, que caracterizaban a la Argentina que moría hacia fines de los $80^{\prime} y$ principios de los $90^{\prime}$.

Em outra parte do artigo, Semán e Vila apontam que esse desenvolvimento é paralelo com o fato de haver presença crescente dos setores socioeconômicos baixos na própria composição das bandas de rock, situação antes excepcional. Os mesmos autores afirmam que o fenômeno "no implica la existencia de un subgénero musical especifico" (p. 231).

Referimo-nos tão extensamente ao texto desses pesquisadores porque ele tem a virtude de explicar como está sendo delimitada essa nova "identidade" no rock argentino, à vez que a leitura crítica dele permite observar como, do interior das mesmas ciências sociais, o fenômeno impõe deslocamentos em relação aos modos em que o gênero vinha sendo abordado e que descrevemos longamente nos quatro itens anteriores.

A formação social argentina mudou radicalmente, aumentando qualitativamente a desigualdade socioeconômica, como aponta o texto de Semán e Vila. E isso tudo acontece dentro do mesmo regime político constitucional. Assim, instalam-se linhas divisórias que já não têm a ver centralmente com atitudes diante do Estado e da repressão, já que embora essa problemática permanece fortemente, os jovens de diferentes classes não a sofrem da mesma maneira. Ao pensar como se representa o abismo social surgido na Argentina, tudo se desloca e ganha complexidade.

O texto de Semán e Vila, de grande espessura teórica e analítica, aponta inicialmente as "temáticas" das letras como traço diferenciador do "rock chabón", mas seu desenvolvimento mostra que seus autores percebem e acompanham um requisito de atender a múltiplas dimensões, que promove a entrada na dimensão discursiva como espaço de filiação de memórias. Um dos momentos mais notáveis nesse sentido é sua análise da letra de "Soy de la esquina", da banda Hermética, em que estabelecem vínculos com a poética do 
tango detectando segmentos que poderíamos chamar de "polifônicos". Ao longo do texto, os autores apontam a necessidade de recorrer a "narrativas" identitárias e percorrem etapas anteriores do rock nacional, em um movimento de revisão que inclui elementos pouco considerados pela tradição crítica que aqui descrevemos, como a criação e seleção de determinados heróis ou personagens.

\section{As abordagens das letras na sua materialidade lingüístico-discursiva. Uma produção "afastada"}

Como antecipamos, são poucos os trabalhos críticos que tomam como objeto as letras de rock com instrumental da análise lingüístico-discursiva ou da crítica poética. Nesta seção nos dedicaremos a eles, começando por alguns que vemos em uma área de passagem entre as abordagens sociológicas e o interesse propriamente discursivo.

\subsection{Interseções}

Dois dos trabalhos que encontramos no nosso levantamento, Díaz (2005) e Fatala (1999), localizam-se na área da "sociossemiótica" e no referencial da teoria do "discurso social" (Angenot, 1998).

Fatala trabalha com material de vídeo-clip, em que às linguagens verbal e musical se acrescenta o imagético. Quando integra na análise observações sobre as letras em interação com a imagem, dá ao lingüístico um tratamento com um louvável grau de especificidade. Destacamos, por exemplo, na sua análise do clip de "Sube a mi voiture", da banda Riff, como aproveita (p. 44) um desdobramento entre instâncias do aparelho de enunciação para exemplificar duas representações do feminino (mujer amada / mujer mercenaria)

O livro de Díaz (2005) é uma das obras de maior porte realizadas sobre o rock nacional. Inspirado em Bourdieu, tenta delimitar o rock nacional como um "campo" dentro do campo maior da produção 
industrial de bens simbólicos. Do começo aponta (p. 22), no que tange à dimensão verbal, que um dos traços que dará ao rock argentino especificidade nos tempos de sua constituição como campo é: "una búsqueda consciente de lo estético, o al menos un acercamiento a ciertas concepciones de "esteticidad" dominantes en campos más legitimados, como el literario." E apóia de imediato essa afirmação em exemplos de diversos procedimentos formais em letras de pioneiros (Manal, Almendra, Los Gatos). Se bem reconhece a ditadura como um período específico marcado por determinadas "condições de enunciabilidade", descreve com zelo as continuidades e descontinuidades, em um panorama que não se apresenta com a simplicidade de um "antes" e um "depois" desse regime. Um exemplo é a seção dedicada à relação do rock com o político, em que aborda (p. 154 a 167) a letrística de Charly García durante o regime militar. O texto tem a grande virtude de organizar sua explicação com base no percurso de um determinado procedimento poético cuja extensão temporal não coincide pontualmente com a existência institucional da ditadura, mas que guarda com ela uma quase contemporaneidade irregular e instigante. $\mathrm{O}$ eixo da reflexão de Díaz nessa parte é o acompanhamento de enunciações que explicitam ou sugerem o ato de "mirar", a existência de um olhar. Assim, o caminho atravessa e relaciona com coerência letras que as abordagens conteudísticas veriam como "tematicamente" diferentes, mas que estão articuladas pela pulsão sinistra do terror nas entrelinhas. E encerra o recorrido dando conta da transformação do olhar:

Ciegos de ver. La mirada de Cassandra, aquella que construía tuertos en un mundo de ciegos, ahora aparece enceguecida de ver algo que está más allá de todo sueño. La mirada de Cassandra se ha trasformado en la mirada de Alicia. El sueño ha devenido pesadilla. (p. 165)

4. As referências são à figura de Cassandra na mitologia grega e de Alice em Lewis Caroll, ambas inseridas por Charly Garcia respectivamente nas composiçōes "El tuerto y los ciegos" (1974) e "Canción de Alicia en el Pais" (1980). 


\subsection{Leituras poéticas, entradas na discursividade}

Vemos na produção de Kozak (1990, 1992 e 2000) e de Monteleone (1992 e 1993) os trabalhos analíticos mais claramente voltados para a especificidade da dimensão verbal no rock argentino. Enquanto os textos de Kozak têm uma estruturação própria do artigo científico, sendo um deles (2000) o capitulo de uma tese, os de Monteleone são ensaios que entram de cheio no discurso da crítica literária, assumindo por momentos eles próprios uma linguagem poética.

Kozak (2000) integra à sua tese de doutorado sobre aspectos da "cultura mediática" argentina contemporânea reflexões sobre o rock e suas letras que vinha elaborando e difundindo em textos anteriores (1990 e 1992). Destacaremos lugares dessas reflexões que incorporam procedimentos de análise discursivo-enunciativa em um texto geral de crítica cultural.

Por uma parte, propõe ler "pegadas" de uma história da constituição e delimitação do gênero nas suas letras, e entre as páginas 177-178 segue o percurso do "naufrágio" anunciado em uma letra pioneira. As intertextualidades polêmicas que detecta em compositores posteriores já tinham sido apontadas por outros leitores do gênero, mas a novidade em Kozak é que ela lê a polêmica como representativa de um modo de impugnar o processo textual de definição, impugnação que estaria ancorada no discurso do rock argentino.

A autora também propõe a possibilidade de localizar "un tipo particular de sujeto de la enunciación que funciona casi como clave del discurso del rock en su conjunto" (p. 180), e na tentativa de caracterizar esse sujeito atribui-lhe os seguintes traços: produzir vozes coletivas, oferecer-se como voz para ser compartilhada por outros, interpelar segundas pessoas e freqüentar limites diferenciadores, como a loucura.

Mas onde cremos que está o mais rico da contribuição de Kozak é na sua proposta de "diseños de significación", construções que surgem "de la combinación de determinados elementos textuales que, a su vez, se ligan a otros tantos elementos extratextuales que entran en la práctica." (p. 182). O "desenho" 
ao qual a autora dedica mais descrição e análise é o do "sobrevivente", tarefa que mostra também, as maiores potencialidades da categoria empregada. Assim começa definindo essa figura:

Si se piensan los medios como institución, la figura sobreviviente se diferencia de la contestataria de la critica a las instituciones por ubicarse imaginariamente no fuera sino dentro de la institución, incluso, en los casos más criticos, muy a su pesar. Desde allí esta estética construye politicas de resistencia que permiten pensar al sujeto del rock en tanto producción de singularidad. De alli que sea ésta la estética rockera más atravesada por los discursos mediados. (p. 186-187)

A figura do sobrevivente permite trabalhar a relação da discursividade com determinações sociopolíticas sem atrelar-se à presença tematizada do político-institucional nas letras, e, em conseqüência, abre possibilidades de captar no seu funcionamento fugidio aquilo que, como dizemos em 2.3 em cima, não se oferece à evidência da "declaração". Assim, por exemplo, os modos em que o terrorismo de estado pode penetrar a discursividade se mostram muito mais sutis do que a menção ou a omissão do horror:

Frente a letras de rock que luego del '83 (y por poco tiempo) nombran madres y desaparecidos, las letras de la figura sobreviviente sólo se nombran a si mismas: cuerpos presentes, establecen una relación elíptica con los cuerpos ausentes. Al nombrarse nombran al cuerpo ausente pero dando rodeos y vueltas, básicamente, por sospecha de las palabras demasiado directas. Quizá, una estética del merodeo le sea más conveniente. (p. 190).

Na extensa análise que desenvolve da conformação dessa figura nas letras é desmontada, também, a totalidade textual, já que com fragmentos de quatro letras diferentes de Charly García são armados dois relatos paralelos. A análise se constrói atendendo ao 
deslocamento de papeis temáticos das personagens em relação com indices temporais.

Em Monteleone (1993) apresenta-se um conjunto de reflexões sobre vários compositores em torno da representação do corpo em letras de cada um deles. Por outra parte, seu trabalho de 1992 trata da poética de um dos letristas mais complexos do rock argentino, Indio Solari, da banda "Patrício Rey y sus Redonditos de Ricota". Em um percurso por fragmentos de suas letras, o crítico elucida a representação da violência institucionalizada na forma de um círculo "infernal" em que o enunciador assume seu lugar de dor e de gozo. O trabalho de Monteleone consegue "amarrar", em um exercício em si mesmo poético, sentidos e figurações onde outras leituras só enxergam dispersão ou arbitrariedade.

\section{Vazios, resistências e migrações.}

Em um texto recente, Alabarces (2005) aponta a necessidade de haver, na pesquisa argentina sobre o rock nacional, uma abordagem que considere de maneira integrada as diferentes linguagens que nele participam, centralmente a musical e a verbal. Com efeito, não há até agora um trabalho que realize algo paralelo ao referencial construído por Tatit (1996), por exemplo, para a música popular brasileira, como integração de ambas as linguagens em categorias específicas como a de "dicção"s.

Neste texto nos ocupamos de outro espaço, se não vazio, quase vago na pesquisa sobre o rock argentino: o da reflexão sistemática sobre sua materialidade lingüístico-discursiva. Fizemo-lo descrevendo as principais tendências na recepção crítica do gênero. E não pretendemos, neste encerramento, sair à procura de causas. Em um campo tão complexo e em que intervêm tantas forças como é o da pesquisa acadêmica e sua difusão, ainda mais sobre um gênero integrado na mídia, mais esclarecedora do que a causatividade pode

5. Há, no entanto, gestos nesse sentido em fragmentos de Díaz (2005), e no modo em que Kozak (2000, p. 185) descreve a "violencia de la palabra". 
ser a observação dos deslocamentos. Por isso queremos terminar referindo-nos a uma resistência e a algumas migrações que nos parecem emblemáticas do panorama encontrado.

A resistência nos remete ao próprio movimento. Com efeito (e só neste momento nos valeremos de nossa longa vivência na Argentina como parte do público "identificado" no rock), cremos que há no movimento algo que "não se deixa" estudar, uma representação bastante fincada nos artistas e no público de que a criatividade dos autores, sobretudo no poético, não pode ser objeto de uma tentativa explicativa ou mesmo descritiva. Observe-se este fragmento do manifesto "Rock: música dura, la suicidada por la sociedad", escrito em 1973 por Luis Alberto Spinetta, que transcrevemos de Beltrán Fuentes (1989, p. 95):

El que recibe debe comprender definitivamente que los proyectos en materia de rock argentino nacen del instinto.

Paradoxalmente, o rock argentino, à vez que enuncia desde sua origem um senso coletivo e um propósito renovador, é portavoz de uma explicação bastante conservadora para a produção artística: o "instinto criador" individual, não passível de interpretação. Tal vez isso se relacione à filiação com uma postura anti-racionalista que tão bem descreve Díaz (2005, p. 204-218), e que chega via, entre outros, dos beatniks.

Por outra parte, a "migração" que mencionamos três parágrafos atrás nos remete ao campo acadêmico argentino que tem estudado o rock, e apresenta uma regularidade que despertou nossa atenção. Três dos pesquisadores de produção mais ampla e significativa sobre o rock argentino que aqui referimos, Alabarces, Díaz e Kozak, provêm da área de Letras, e dela passaram, total ou parcialmente, em direção a outro campo mais ou menos vizinho. Hoje, Pablo Alabarces dedica-se plenamente à Sociologia na Facultad de Ciencias Sociales da UBA. Cláudio Díaz é hoje docente de Sociologia del Discurso na UNC. Claudia Kozak coordena um projeto de pesquisa estabelecido na Facultad de Ciencias Sociales e relacionado à área de comunicação social. De algum modo, o contato 
com o objeto rock aparece vinculado a um maior ou menor deslocamento disciplinar em uma direção regular.

Sinais de resistência de um objeto, migrações de sujeitos de (e em) um saber, são apenas sintomas achados no percurso por um campo de pesquisa que, como antecipamos em 1, é recortado a partir do olhar de um locus disciplinar determinado. Se enxergados no contexto mais geral, fora do escopo deste trabalho, dos espaços acadêmicos e dos campos cultural, político e educativo da Argentina do final do século, cremos que diriam algo sobre as prioridades, princípios de classificação e relações de força nesses campos.

\section{Bibliografia}

ALABARCES, P. 1993. Entre gatos y violadores. El rock nacional en la cultura argentina. Buenos Aires: Ed. Colihue.

2005. "Once apuntes para una sociologia de la música popular en Argentina". In: Actas del VI Congreso Latinoamericano IASPM (International Association for the Study of Popular Music).http://www.iaspm.net/start.html (acesso 21-107).

ANGENOT, M. 1998. Interdiscursividades. De hegemonias y disidencias. Córdoba: Ed. de la UNC.

BELTRÁN FUENTES, A. 1989. La ideología antiautoritaria del rock nacional. Buenos Aires: Centro Editor de América Latina.

BUSTOS CASTRO, P. 1994. Rocanrol. El recital: los militantes del bardo. In: MARGULIA, M. (org.), p. 51-76.

CICALESE, G.; NOGUEIRA, S. 1998. La música argentina en los períodos $1982 / 85$ y $1993 / 97$. Una misma geografia, dos visiones del mundo. In: DE NAPOLI, C. et. al., p. 130-160.

DE NAPOLI, C. 1998. La maga en coma. Fragmentos sobre rock y literatura en la Argentina de hoy. In: DE NAPOLI et. al., p. 9-27.

DE NAPOLI, C. et. al. 1998. Treinta años de música para jóvenes. Buenos Aires: Ed. De la Flor.

DÍAZ, C. 2005. Libro de viajes y extravios: un recorrido por el rock argentino 1965-1985. Córdoba: Narvaja Editor. 
DI MARCO, A. 1994. Rock: universo simbólico y fenómeno social. In: MARGULIS, M. (org.), p. 31-49.

FATALA, N. 1999. Identidades genéricas y periferia discursiva: los vídeo clips del rock nacional. In: DALMASSO, M. T.; BORIA, A. (org): El discurso social argentino. Vol. 3: Marginación y periferia. Córdoba: Ed. Topo Grafia, p. 25-54.

FOLLARI, R. 1998. Rock nacional y posmodernidad. Mendoza: 52 p. Tesina de Licenciatura en Comunicación Social. Facultad de Ciencias Políticas y Sociales. Universidad Nacional de Cuyo.

GOBELLO, J.; OLIVERI, M. 2001. Tangueces y lunfardismos del rock argentino. Buenos Aires: Ed. Corregidor.

GUIMARÃES, E. 2002. Semântica do acontecimento. Campinas: Ed. Pontes.

KOZAK, C. 1990. Rock en letras. Buenos Aires: Libros del Quirquincho.

1992. "Estética del sobreviviente: una letra contemporánea." Espacios de crítica y producción, Buenos Aires: Facultad de Filosofia y Letras, UBA, n. 11, p. 23-28.

2000. Discursos mediados. Transformaciones de las prácticas artístico-verbales en el marco de la cultura mediática argentina contemporánea. Buenos Aires: $328 \mathrm{p}$. Tese de Doutorado inédita. Facultad de Filosofia y Letras, UBA.

MARGULIS, M. (org.). 1994. La cultura de la noche. La vida nocturna de los jóvenes en Buenos Aires. Buenos Aires: Ed. Espasa.

MARTÍNEZ MENDOZA, R. 1994. El rock nacional y sus contradicciones. ¿Circo criollo del rocanrol? In: MARGULIS, $M$. (org.), p. 93-110.

MOLINARI, V. 2000. Una mirada sobre el rock nacional de fin de siglo... cuerpos, música y discursos. Em: WORTMAN, A. (org.): Pensar las clases medias. Consumos culturales y estilos de vida urbanos en la Argentina de los noventa. Buenos Aires: Ed. La Crujía, p. 207-215.

MONTELEONE, J. 1992. "El infierno encantador. Violencia y poesía del rock." Espacios de crítica y producción. Buenos Aires: Facultad de Filosofia y Letras, UBA, n. 11, p. 29-33. 
MONTELEONE, J. 1993. "Cuerpo constelado. Sobre la poesía del rock argentino." Cuadernos Hispanoamericanos, Madri, n. 517519, p. 401-420.

MUKAROWSKY, J. 1977. Escritos de estética y semiótica del arte. Barcelona: G. Gili.

NEILA, M. 2002. Rock nacional de los 90. Hibridez y denuncia social. Demoliendo cuarteles. Mendoza: 66 p. Tesina de Licenciatura en Comunicación Social. Facultad de Ciencias Políticas y Sociales. Universidad Nacional de Cuyo.

OGANDO, M. 1998. El rock nacional en la identidad juvenil. Cruces, permanencias y reciclajes en la formación de una cultura. In: DE NAPOLI, C. et. al., p. 188-208.

OTERO, H. 1998. De las botas al rimmel. Contrastes entre la escena musical argentina y la inglesa en la primera mitad de la década del 80. In: DE NAPOLI, C. et. al., p. 209-224.

PÁRAMOS, R. 1998. Así es el rock nacional. Claves para ingresar en el imaginario del rock y en la identidad de los jóvenes. In: DE NAPOLI et. al., p. 79-106.

PÊCHEUX, M. 1990. Lecture et mémoire: projet de recherche. In: L' inquiétude du discours. Textes de Michel Pêcheux choisis et présentés par Denise Maldidier. Paris: Éditions des Cendres, p. 285-293.

SEMÁN, P.; VILA, P. 2001. Rock chabón e identidad juvenil en la Argentina neoliberal. In: AA.VV.: Los noventa. Política, sociedad y cultura en América Latina y Argentina de fin de siglo. Buenos Aires: FLACSO-Eudeba, p. 225-258.

SOSA, M. 1997. Rock predicativo. Cuando las palabras son balas. Buenos Aires: $82 \mathrm{p}$. Tesina de Licenciatura en Ciencias de la Comunicación. Facultad de Ciencias Sociales. UBA.

TATIA, L. 1996. O cancionista. Composições de canções no Brasil. São Paulo: EDUSP.

VILA, P. 1985. Rock nacional. Crónicas de la resistencia juvenil. In: JELIN, E. (org.): Los nuevos movimientos sociales. Buenos Aires: Centro Editor de América Latina, p. 83-156.

1987. El rock. Música argentina contemporánea. Punto de Vista, Buenos Aires, n. 30, p. 23-29. 